\title{
Intramedullary spinal cord tumors: a review of current and future treatment strategies
}

\author{
*Matthew K. Tobin, BS,' Joseph R. Geraghty, BS, ${ }^{1}$ Herbert H. Engelhard, MD, PhD, ${ }^{1}$ \\ Andreas A. Linninger, $\mathrm{PhD},{ }^{2}$ and Ankit I. Mehta, $\mathrm{MD}^{1}$ \\ Departments of ${ }^{1}$ Neurosurgery and ${ }^{2}$ Bioengineering, University of Illinois at Chicago, Illinois
}

\begin{abstract}
Intramedullary spinal cord tumors have low incidence rates but are associated with difficult treatment options. The majority of patients with these tumors can be initially treated with an attempted resection. Unfortunately, those patients who cannot undergo gross-total resection or have subtotal resection are left with few treatment options, such as radiotherapy and chemotherapy. These adjuvant treatments, however, are associated with the potential for significant adverse side effects and still leave patients with a poor prognosis. To successfully manage these patients and improve both their quality of life and prognosis, novel treatment options must be developed to supplement subtotal resection. New research is underway investigating alternative therapeutic approaches for these patients, including directed, localized drug delivery and nanomedicine techniques. These and other future investigations will hopefully lead to promising new therapies for these devastating diseases.
\end{abstract}

http://thejns.org/doi/abs/10.3171/2015.5.FOCUS15158

KEY WORDS intramedullary spinal cord tumors; resection; nanomedicine; astrocytomas; ependymoma; review

I NTRAMEDULLARY spinal cord tumors (IMSCTs) are rare neoplasms of the CNS and have been a significant clinical challenge due to the lack of a clear standard of care, limited therapeutic options, and challenges of drug delivery. IMSCTs account for $2 \%-4 \%$ of all CNS tumors, with ependymoma being the most common in adults and astrocytomas being the most common in children and adolescents. ${ }^{10}$ Overall, ependymomas are the most frequent IMSCTs, followed by astrocytomas and then miscellaneous tumors including hemangioblastomas, gangliogliomas, germinomas, primary CNS lymphomas, and melanomas (Table 1). Although rare, IMSCTs can also develop as a result of metastasis from a primary malignancy.

While most IMSCTs are benign, low-grade (WHO Grades I and II) tumors, many vary in histology and 7\%$30 \%$ of astrocytomas are considered malignant..$^{11,13}$ IMSCTs can be found in any location throughout the length of the spinal cord; however, they are most common at the cervi- cal level (33\%), followed by the thoracic (26\%) and lumbar (24\%) levels. ${ }^{29}$ The higher incidence of IMSCTs at the cervical level may be related to the higher level of gray matter present at that level. MRI is recommended for the identification and evaluation of IMSCTs, with intensities and contrast-enhancement varying depending on the tumor type and signal.

The most common presenting symptom of IMSCT is back pain, which may be diffuse or radicular in nature. Diagnosis is especially difficult in children, where IMSCTs may remain asymptomatic for a long period of time or cause nonspecific complaints. ${ }^{28}$ The character of the pain varies, but is commonly reported to worsen at night. IMSCTs can also impinge on somatosensory and motor systems, causing dys- and paresthesias, spasticity, and weakness. Loss of bowel and bladder function can also occur at a later stage and is the least common presenting symptom. ${ }^{54}$ Symptoms in children may be perceived as clumsiness or attributed to

ABBREVIATIONS BSCB = blood-spinal cord barrier; CED = convection-enhanced delivery; EGFR = epidermal growth factor receptor; Fn14 = protein fibroblast growth factor-inducible 14; GCT = germ cell tumor; GTR = gross-total resection; IMSCT = intramedullary spinal cord tumor; STR = subtotal resection; VEGF = vascular endothelial growth factor; $\mathrm{VHL}=$ von Hippel-Lindau.

SUBMITTED March 30, 2015. ACCEPTED May 19, 2015

INCLUDE WHEN CITING DOI: 10.3171/2015.5.FOCUS15158.

DISCLOSURE Dr. Mehta reports that he receives funding from an AO Foundation Young Investigator Award.

* Mr. Tobin and Mr. Geraghty contributed equally to this work. 
TABLE 1. Intramedullary spinal cord tumors

\begin{tabular}{llll}
\hline \multicolumn{1}{c}{ Tumor } & \multicolumn{1}{c}{ Incidence } & \multicolumn{1}{c}{ Location } & Prognosis \\
\hline Ependymoma & Most common $(50-60 \%$ of IMSCTs $)$ & Cervical $>$ thoracic $>$ lumbar & Good \\
\hline Myxopapillary ependymoma & Rare & Filum terminale \& conus medullaris & Excellent \\
\hline Astrocytoma & Second most common & Cervical $>$ thoracic $>$ lumbar & Poor \\
\hline Hemangioblastoma & $\begin{array}{l}\text { Very rare; increased incidence in VHL disease } \\
\text { patients }\end{array}$ & Cervical $>$ thoracic $>$ lumbar & Excellent \\
\hline GCT & Very rare & Cervical $>$ thoracic $>$ lumbar & Good \\
\hline Ganglioglioma & Rare & Cervical $>$ thoracic $>$ lumbar & Good \\
\hline CNS lymphoma & Rare & Cervical $>$ thoracic $>$ lumbar & Poor \\
\hline Melanoma & Very rare & Cervical $>$ thoracic $>$ lumbar & Poor \\
\hline
\end{tabular}

trivial injuries, and scoliosis is present in one-third of patients. ${ }^{28}$

Evidence-based treatment of IMSCTs (Table 2) primarily involves resection, with radiotherapy and chemotherapy often reserved for tumor recurrence, high-grade and infiltrative tumors, or when resection is contraindicated. Preoperative neurological status and tumor histology are considered the best predictors of outcome, with tumor histology shown to be predictive of extent of resection, functional neurological outcomes, and recurrence..$^{30}$ Resection is generally considered a good predictor of outcome. Recent studies, however, have shown that surgical intervention for the management of astrocytoma is associated with higher rates of long-term neurological complications with no derived benefit for patients. ${ }^{5}$

The standard of care for most cases of IMSCT is resection, which has improved with the development of modern neurosurgical instrumentation, use of the operating microscope, as well as the measurement of intraoperative motor and somatosensory evoked potentials. However, resection of IMSCT is generally dependent on the presence or absence of a clear plane of dissection. While ependymomas typically have a clear plane between the tumor and spinal cord parenchyma, astrocytomas tend to be more infiltra- tive, lacking a good plane of dissection. ${ }^{14}$ This limits the ability for gross-total resection (GTR) for intramedullary astrocytomas, as any attempt at GTR may damage spinal pathways, leading to postoperative neurological deficits involving both motor and sensory systems.

Adjuvant radiotherapy is recommended when resection is contraindicated, or for high-grade tumors that are not amenable to GTR. The role of radiotherapy, though, is controversial, as there have been reports that suggest a positive outcome while others suggest no benefit despite its routine use in the clinical setting. ${ }^{60}$ Additionally, radiotherapy can have several adverse effects, including radiation myelopathy, impaired spine growth, spinal deformities, radiation necrosis, vasculopathy, changes to the normal spine parenchyma, and a $25 \%$ risk of secondary tumors in 30 years. ${ }^{6} 10$ These longer-term consequences can be particularly adverse in children and adolescents.

Since children are more sensitive to the adverse effects of IMSCTs, the role of chemotherapy has gained further appreciation. Chemotherapy has historically been used only when resection and adjuvant radiotherapy were contraindicated or unsuccessful. ${ }^{10}$ Some of the limitations of chemotherapeutic agents include the inability of large molecules to bypass the blood-spinal cord barrier (BSCB),

TABLE 2. Current evidence-based recommendations for the treatment of IMSCTs

\begin{tabular}{|c|c|c|}
\hline Tumor & Treatment & Evidence-Based Classification* \\
\hline Ependymoma & $\begin{array}{l}\text { Primary: resection } \\
\text { Secondary: RT } \\
\text { Secondary: chemo }\end{array}$ & $\begin{array}{l}\text { Class I, Level of Evidence: C } \\
\text { Class Ila, Level of Evidence: C } \\
\text { Class Ilb, Level of Evidence: C }\end{array}$ \\
\hline Myxopapillary ependymoma & Surgical resection & Class I, Level of Evidence: C \\
\hline Astrocytoma & $\begin{array}{l}\text { Primary: resection } \\
\text { Secondary: RT } \\
\text { Secondary: chemo }\end{array}$ & $\begin{array}{l}\text { Class Ilb, Level of Evidence: C } \\
\text { Class Ila, Level of Evidence: C } \\
\text { Class Ilb, Level of Evidence: C }\end{array}$ \\
\hline Hemangioblastoma & Surgical resection & Class I, Level of Evidence: C \\
\hline GCT & $\begin{array}{l}\text { Primary: resection } \\
\text { Secondary: RT (germinomas) } \\
\text { Secondary: chemo (non-germinomatous GCT) }\end{array}$ & $\begin{array}{l}\text { Class I, Level of Evidence: C } \\
\text { Class Ila, Level of Evidence: C } \\
\text { Class Ila, Level of Evidence: C }\end{array}$ \\
\hline Ganglioglioma & Surgical resection & Class I, Level of Evidence: C \\
\hline CNS lymphoma & Intrathecal chemo & Class Ilb, Level of Evidence: C \\
\hline Melanoma & $\begin{array}{l}\text { Primary: resection } \\
\text { Secondary: RT }\end{array}$ & $\begin{array}{l}\text { Class I, Level of Evidence: C } \\
\text { Class Ilb, Level of Evidence: C }\end{array}$ \\
\hline
\end{tabular}


CSF pulsations, and the widespread systemic effects of the drugs. Allen et al. ${ }^{2}$ reported that $75 \%$ of patients experienced significant chemotherapy-associated toxicity, with 1 patient dying from renal failure and another developing bilateral hearing loss. While we generally follow the guidelines outlined in Table 2 for the management of these tumors, our proposed management strategies are discussed in Table 3. With all of this said, the localized nature of IMSCT and lack of positive outcomes with current treatment regimens make it an appealing target for novel therapies, such as localized drug delivery mechanisms capable of bypassing the BSCB and targeted drug delivery, that avoid systemic side effects (Table 4).

\section{Intramedullary Spinal Cord Tumors Ependymomas}

Ependymomas are rare, unencapsulated glial tumors of the brain, but they represent the most common form of IMSCT in adults and account for approximately $50 \%-$ $60 \%$ of all intramedullary tumors. ${ }^{43}$ Ependymomas develop from ependymal cells, which are the epithelial-like cells lining the ventricles of the brain as well as the central canal of the spinal cord. Histologically, ependymomas can be classified into 4 types: myxopapillary ependymoma (WHO Grade I), subependymoma (WHO Grade I), ependymoma (WHO Grade II), and anaplastic ependymoma (WHO Grade III). Myxopapillary ependymomas account for up to $50 \%$ of ependymoma cases, typically arise from the filum terminale, and are usually located in the cauda equina while the other 3 subtypes follow the normal distribution of IMSCTs and are most often found in the cervical or thoracic spinal cord. ${ }^{56}$ Most ependymomas are slow growing and display a benign pathology; however, anaplastic ependymomas tend to be rapidly growing and demonstrate more aggressive behavior. Overall, ependymomas occur more commonly in males presenting with chronic back pain. ${ }^{1}$

On MRI, ependymomas are centrally located and can be seen as a localized enlargement of the spinal cord on T1- and T2-weighted images. Ependymomas will appear hyperintense on T2-weighted and FLAIR images and hypo- or isointense on T1-weighted images, although the use of FLAIR for imaging lesions of the spinal cord has been studied much less than that for lesions of the brain. ${ }^{1}$ Myxopapillary ependymomas differ slightly in that they may appear hyperintense on T1-weighted images as well. All types appear to show heterogeneous enhancement with contrast, and cyst formation and syrinx are common especially at the cervical level. ${ }^{1}$ Cysts form in both the rostral and caudal directions from the enhancing mass.

In most cases, ependymomas have an easily identified plane of dissection, and thus GTR is the primary form of treatment. There are several studies showing that the extent of resection is a strong predictor of overall survival, with $90 \%-100 \%$ of patients showing improvement following complete resection. ${ }^{20}$ However, GTR is not achieved in most patients due to most ependymomas being located in areas that, if resected, would decrease neurological function. ${ }^{6}$ GTR in cases of myxopapillary ependymomas has been controversial, but a recent study found that GTR is associated with lower overall recurrence compared with subtotal resection (STR), but also states that there is no evidence whether GTR contributes to better functional outcome in patients. ${ }^{17}$ While adjuvant radiotherapy is not recommended for completely resected tumors, it has been traditionally used following STR, recurrent tumors, or when surgery cannot be performed. The benefit of radiotherapy has also been contested, with some studies reporting a 5-year survival rate of $70 \%$ for patients receiving adjuvant irradiation compared with $20 \%$ for patients treated with surgery alone. ${ }^{6}$ More recent studies suggest that radiotherapy is not associated with lower overall recurrence regardless of the extent of resection. ${ }^{17}$

While there are few data supporting the use of chemotherapy in the treatment of ependymoma, the high incidence of these tumors in children makes it an important option for therapeutic development. Chemotherapy has, for the most part, been studied in recurrent intracranial ependymoma and has been shown to have a modest effect; however, its role in IMSCTs remains to be elucidated. ${ }^{8}$ In the 2002 study by Chamberlain, ${ }^{8}$ the topoisomerase- 2 inhibitor etoposide was well tolerated and had a partial response in 2 of 10 treated patients (20\%). The small number of patients limits the study but highlights the fact that more studies need to be done on various chemotherapeutic agents, like etoposide.

TABLE 3. The authors' proposed management strategy for IMSCTs

\begin{tabular}{ll}
\hline \multicolumn{1}{c}{ Tumor } & $\begin{array}{c}\text { Attempt GTR based on plane of dissection \& intraop neuromonitoring; if STR performed, add } \\
\text { adjuvant RT }\end{array}$ \\
\hline Ependymoma & $\begin{array}{l}\text { Attempt GTR based on plane of dissection \& intraop neuromonitoring } \\
\text { Myxopapillary ependymoma }\end{array}$ \\
\hline Astrocytoma & $\begin{array}{c}\text { Assess plane of dissection \& perform STR (biopsy); if there is significant residual tumor or recur- } \\
\text { rence, add RT }\end{array}$ \\
\hline Hemangioblastoma & $\begin{array}{c}\text { Preop spinal cord angiography for possible embolization of vascular feeders; GTR w/ a good } \\
\text { plane of dissection }\end{array}$ \\
\hline GCT & Assess CSF for germ cell markers (hCG, AFP, PLAP); RT \\
\hline Ganglioglioma & GTR; if there is recurrence, consider RT \\
\hline CNS lymphoma & High-dose methotrexate \& temozolomide; diagnosis made w/ biopsy \\
\hline Melanoma & GTR; postop RT \\
\hline AAFP a a
\end{tabular}

AAFP = alpha-fetoprotein; $h C G$ = human chorionic gonadotropin; PLAP = placental alkaline phosphatase. 
TABLE 4. Advantages and disadvantages of adjuvant treatment modalities after resection

\begin{tabular}{|c|c|c|}
\hline Treatment Modality & Advantages & Disadvantages \\
\hline RT & $\begin{array}{l}\text { Localizable; noninvasive; avoids systemic effects } \\
\text { of drug therapy }\end{array}$ & $\begin{array}{l}\text { Increased risk of secondary tumor; time intensive; } \\
\text { increased risk of long-term complications, includ- } \\
\text { ing radiation necrosis, myelopathy, spine deformity, } \\
\text { vasculopathy; likelihood of complications increased } \\
\text { in pediatric population }\end{array}$ \\
\hline Chemo & No clear advantages & $\begin{array}{l}\text { Inability to cross the BSCB; not localizable; lack of } \\
\text { parenchymal penetration; increased off-target } \\
\text { effects; low efficacy }\end{array}$ \\
\hline $\begin{array}{l}\text { Focused ultrasound } \\
\text { surgery }\end{array}$ & Localizable; noninvasive; real-time MRI guidance & $\begin{array}{l}\text { Long procedure time; relatively new technology, no } \\
\text { substantial data about long-term complications; } \\
\text { healthy tissue equally affected by ultrasound }\end{array}$ \\
\hline CED & $\begin{array}{l}\text { Consistent drug concentration; lower systemic } \\
\text { side effects }\end{array}$ & $\begin{array}{l}\text { Invasive; long infusion time; increased risk for spinal } \\
\text { cord damage; large volume delivery in a space- } \\
\text { limiting environment }\end{array}$ \\
\hline $\begin{array}{l}\text { Drug-eluting polymer } \\
\text { wafers }\end{array}$ & $\begin{array}{l}\text { Localizable; sustained drug release; biocompat- } \\
\text { ible; defined release parameters }\end{array}$ & $\begin{array}{l}\text { Invasive; low drug penetration; dosage limited by size } \\
\text { of implant; limited treatment period }\end{array}$ \\
\hline Nanomedicine & $\begin{array}{l}\text { Highly localizable; ability to guide drug-containing } \\
\text { nanoparticles; increased rate of parenchy- } \\
\text { mal penetration; ability to bypass BSCB; no } \\
\text { systemic effects }\end{array}$ & \\
\hline
\end{tabular}

\section{Astrocytomas}

Intramedullary astrocytomas are glial tumors responsible for approximately $60 \%$ of all spinal cord tumors in children and adolescents, despite affecting patients of all ages ${ }^{45}$ Most spinal cord astrocytomas are low grade (WHO Grade II) and generally considered to be less aggressive than those in the brain. Of a total of 86 studied astrocytoma cases, Raco et al. ${ }^{54}$ found $48 \%$ to be WHO Grade II, followed by $31 \%$ to be WHO Grade I, and $21 \%$ to be WHO Grade III to IV. WHO Grade I lesions represent pilocytic astrocytomas, a slow-growing tumor associated with cyst formation. Some studies have suggested that pilocytic astrocytomas represent the most common subtype in children, though these studies are limited by their sample sizes. ${ }^{61}$ Grade III and IV astrocytomas carried a poor prognosis with a mean survival of 15.5 months. ${ }^{54}$ These lesions are the most aggressive and infiltrative class of astrocytomas.

The presentation of these lesions varies, with pain being one of the earliest symptoms similar to ependymomas. Since these lesions tend to affect pediatric populations, certain symptoms in children are indicative of astrocytoma. These include children complaining of pain at night that wakes them up, abdominal pain, motor deficits or regression, and scoliosis. ${ }^{28}$ Combined together, presentation in children is often nonspecific and may require extensive diagnostic workup to rule out other etiologies before suspecting astrocytoma.

On MRI, astrocytomas are difficult to distinguish from other types of intramedullary tumors. While usually hypo- or isointense on T1-weighted images and hyperintense on T2-weighted images, their asymmetry and slightly off-center location may help distinguish them from other tumor types. ${ }^{1}$ Similar to ependymomas, astrocytomas show heterogeneous enhancement with contrast that makes it hard to distinguish between ependymomas and astrocytomas based on MRI alone. For this reason, biopsy and histology might be considered the best methods for distinguishing astrocytomas from ependymomas and planning treatment options.

Astrocytomas typically lack a clear plane of dissection and demonstrate a much more infiltrative nature than ependymomas. For this reason, GTR is often not achieved, and astrocytomas are associated with a poorer prognosis. In the study by Raco et al., ${ }^{54} 0 \%$ of WHO Grade III to IV astrocytomas were able to undergo GTR, while only $12 \%$ of WHO Grade II tumors were completely resected. In a study by Babu et al., ${ }^{5}$ a total of 46 patients underwent laminectomy over the regions with solid tumor, and maximal resection was attempted while monitoring sensory and motor evoked potentials. The study found that $37 \%$ of patients had a worse postoperative neurological outcome compared with baseline before operation. ${ }^{5}$ This is most likely due to the infiltrative nature of the tumor, which risks damage to the normal spinal cord parenchyma during resection. In current practice, attempting GTR is not recommended; however, partial resection or STR can be attempted. This increases the likelihood of recurrence as microscopic remnants of the tumor may remain in the spinal cord parenchyma following resection. Karikari et al. ${ }^{30}$ noted that $47.6 \%$ of patients with primary spinal cord astrocytomas had a recurrence, all of whom had originally underwent STR. This is much higher than the rate of recurrence for ependymomas of $7.3 \% .^{30}$

If recurrence of astrocytoma does occur, radiotherapy is the next course of treatment. ${ }^{10}$ However, the use of radiotherapy for astrocytomas, especially low-grade astrocytomas, is controversial since they commonly affect children and adolescents. All of the risks associated with radiotherapy, combined with the frequent inability 
to achieve GTR, point toward chemotherapy as a viable option for treating astrocytomas. This is especially true when surgery and radiotherapy have been unsuccessful. Studies of chemotherapeutic agents for astrocytomas are very limited, and further studies are warranted. Some studies have suggested a possible therapeutic value for the DNA-alkylating drug temozolomide. Chamberlain et al. ${ }^{9}$ showed that temozolomide treatment led to $27 \%$ progression-free survival at 2 years with a median survival of 23 months. As temozolomide has shown some efficacy in treating intracranial astrocytomas, such as glioblastoma, it has been used in treating astrocytomas within the spinal cord as well. ${ }^{10,40}$ Despite this modest benefit, there were also associated systemic toxicities, including constipation, fatigue, neutropenia, lymphopenia, and thrombocytopenia in several patients. ${ }^{9}$ These adverse effects associated with standard chemotherapy treatments are dependent on the systemic toxicity associated with the agents used. Thus, to develop effective treatments for astrocytoma, larger studies on chemotherapy, as well as therapies that localize drug delivery to specific spinal cord segments, are necessary.

\section{Hemangioblastomas}

Intramedullary hemangioblastomas are rare, benign tumors of mesenchymal origin that originate from the vascular system within the spinal cord. Intramedullary hemangioblastomas account for 3\%-4\% of all IMSCTs and are the third most frequent after ependymomas and astrocytomas. ${ }^{33}$ Hemangioblastomas most commonly present in the posterior fossa (83\%); however, approximately $13 \%$ are found within the spinal cord. ${ }^{48}$ While they do not develop from the intrinsic cells of the spinal cord, their close association with the vasculature that nourishes the spinal cord can lead to the rare development of intramedullary tumor. For this reason, they tend to possess a high degree of vascularity and angiogenesis during growth.

Hemangioblastoma is strongly associated with von Hippel-Lindau (VHL) disease, and approximately 10\%-30\% of patients diagnosed with spinal cord hemangioblastoma will also have VHL disease. ${ }^{10}$ Patients with VHL disease typically present with multiple hemangioblastomas in addition to other abnormalities such as renal cell carcinoma, pheochromocytoma, pancreatic cysts, and others. ${ }^{48}$ The presence of multiple hemangioblastomas along with these other abnormalities may thus point toward VHL disease. In patients with VHL disease, gene mutation results in the enhanced transcription of several genes, including vascular endothelial growth factor (VEGF), which perhaps contributes to the development of vascular tumors such as hemangioblastomas. ${ }^{39}$

Intramedullary hemangioblastomas tend to develop in the dorsal portion of the spinal cord and thus present with progressive sensory deficits, particularly proprioceptive deficits. ${ }^{10}$ Due to the high vascularity of the tumor, there is also a risk of hemorrhage. Although rare, hemorrhage from hemangioblastoma can be subarachnoid hemorrhage $(73 \%)$ or intramedullary hemorrhage $(27 \%) .{ }^{64}$ Unlike astrocytomas, hemangioblastomas can be differentiated from ependymomas using MRI by the presence of hypervascularity along with tumor enhancement. ${ }^{10}$ Further- more, due to the altered vasculature within the spinal cord, unusual enlargement of the spinal cord may be observed due to edema. ${ }^{43}$

Similar to other IMSCTs, resection is the primary treatment for intramedullary hemangioblastomas. Hemangioblastomas typically exhibit a clear dissection plane that allows for GTR. ${ }^{10}$ Due to the vascularity of the lesion, resection does pose a risk of intraoperative bleeding; however, recent studies have shown that hemorrhage from feeder arteries is generally not an issue due to techniques such as preoperative embolization and temporary artery occlusion. ${ }^{66}$ Therefore, resection appears to be the best option for patients with hemangioblastoma.

The use of radiotherapy in the treatment of hemangioblastomas is very limited, while chemotherapy has been studied even less. Antiangiogenic therapy using the VEGF receptor-2 inhibitor SU5416 was shown to be somewhat effective in patients with VHL disease. ${ }^{39}$ In contrast, the use of the monoclonal antibody bevacizumab to inhibit the VEGF receptor was shown to be ineffective, resulting in increased tumor invasiveness following antiangiogenic therapy. ${ }^{63}$ Taken together, this may imply that some hemangioblastomas might show responsiveness to angiogenesis inhibitors, while others may not, depending on the level of upregulation of the VEGF gene.

\section{Germ Cell Tumors}

Germ cell tumors (GCTs) of the CNS are made up of cells similar to the germinal cells that develop in the gonads. GCTs represent approximately $1 \%$ of brain or spinal cord tumors in Europe and the United States, with higher rates of incidence in other geographical regions such as Japan (3\%) and East Asia (12.5\%). ${ }^{4}$ The rates of primary intramedullary GCTs are even lower. There are 2 types of GCT: nongerminomatous GCT and germinoma. Patients with primary intramedullary germinomas typically present with sensory and motor deficits of the lower extremities that can progress to include gait disturbance and urological dysfunction. ${ }^{38}$ MRI typically shows an expanding mass (often at the lower thoracic level), contrast enhancement with T1- and T2-weighted MRI can vary, and focal spinal cord atrophy may be an important sign. ${ }^{38}$

Germinomas have been shown to be radiosensitive, with some studies suggesting 5-year survival rates of $65 \%-95 \%$ with irradiation alone. ${ }^{6}$ Germinomas are sensitive to chemotherapy as well. ${ }^{6}$ In contrast, nongerminomatous GCTs show little sensitivity to radiotherapy alone and are often treated in combination with chemotherapy. ${ }^{6}$ Since intracranial germinomas seem to be responsive to the chemotherapeutic drugs cisplatin and etoposide, attempts have been made to treat intraspinal germinomas in the same manner. ${ }^{32}$ A recent study by Kinoshita et al. ${ }^{32}$ found that in a patient with multiple spinal cord germinomas, this combination therapy was effective in reducing tumors at multiple levels. Other studies have suggested that combination therapy will allow for a reduction in the necessary radiation dose and still lead to complete remission. ${ }^{4}$ Thus, chemotherapy might provide an alternate option in the treatment of intramedullary germinomas that could avoid the negative side effects associated with radiation treatment. 


\section{Gangliogliomas}

Gangliogliomas are rare tumors from both neuronal and glial origins that are composed of glial and ganglion cells. Most gangliogliomas are intracranial in the supratentorial space, with intramedullary spinal cord gangliomas being very rare. ${ }^{69}$ They are typically benign, slow-growing tumors (WHO Grade I or II), although malignant transformation has been shown and is presumed to involve the glial component of the tumor. ${ }^{3}$ Of interest, a recent study on 27 infratentorial gangliogliomas found that there were 2 distinct categories: $59 \%$ were classic gangliogliomas, and the remaining $41 \%$ were described as having a high similarity to pilocytic astrocytomas but with the addition of some cells of ganglion cell origin. ${ }^{22}$

Intramedullary gangliogliomas are usually located within the cervical level, larger than other types of IMSCTs, and difficult to distinguish on MRI. Yang et al. ${ }^{69}$ found that $39 \%$ of patients with intramedullary ganglioglioma also presented with obvious scoliosis, which may be indicative of this type of lesion. These tumors tend to mostly affect the pediatric population, and in a recent study of 348 children were found to affect mostly older children and young teenagers. ${ }^{12}$

Similar to most IMSCTs, resection is the primary treatment of choice. GTR for spinal gangliogliomas is achieved at a much higher rate (83.3\%) compared with intracranial tumors. ${ }^{12}$ However, due to the large size of these tumors and the fact they are often located in the cervical spinal cord, attempting GTR can be risky. Thus, STR may be a more effective treatment in regards to minimizing neurological dysfunction following resection, although more studies need to be done. ${ }^{69}$ Adjuvant and postoperative radiotherapy are typically not recommended, except in some cases of recurrence, and the use of chemotherapy has only been extrapolated from its use for intracranial gangliogliomas. ${ }^{10}$ Despite these treatments, spinal gangliogliomas have a higher relative risk of recurrence than both cerebral and brainstem gangliogliomas and have a 10-year survival rate of $83 \%$. 333

\section{CNS Lymphoma}

Intramedullary spinal cord lymphoma is a rare form of primary lymphoma and can occur anywhere in the CNS. It can originate in the spinal cord, accompany tumors in other locations throughout the CNS, or occur as a part of systemic lymphoma. ${ }^{18}$ It is usually an aggressive nonHodgkin lymphoma of B-cell origin. ${ }^{31}$ T1-weighted MRI shows homogeneous contrast enhancement in an enlarged area of the spinal cord, while diffusion-weighted and T2weighted MRI demonstrate hyperintensity. ${ }^{10}$ Due to its lack of localization, the primary treatment for intramedullary lymphoma and other lymphomas of the neuraxis is the chemotherapeutic agent methotrexate; however, recurrence is common and often occurs within 2 months. ${ }^{18}$ High-dose methotrexate-based therapy has been shown to be effective in elderly patients suffering from primary CNS lymphomas, and even more so when combined with alkylating agents such as temozolomide. ${ }^{31}$ Thus, the development of chemotherapeutic agents for the treatment of primary CNS lymphoma is especially appealing, given that its diffuse nature makes resection and radiotherapy more challenging.

\section{Melanoma}

Primary melanomas of the spinal cord are very rare and account for about $1 \%$ of all melanomas, with diagnosis dependent on the absence of melanoma outside of the CNS and histological confirmation of pigmented tumors. ${ }^{16}$ Patients with primary intramedullary melanoma will experience similar symptoms as other intramedullary tumors. However, melanomas often develop more rapidly than other IMSCTs, so the progression of symptoms will be rapid. ${ }^{10}$ On MRI, distinguishing intramedullary melanomas from other IMSCTs is difficult; however, their patterns on T1- and T2-weighted images are different from other IMSCTs and may prove useful. Melanomas typically display hyperintensity on T1-weighted images due to the presence of melanin, while T2-weighted images are generally hypo- or isointense. ${ }^{16}$

While resection is the primary treatment option for intramedullary melanoma, GTR is difficult and most patients will require postoperative radiotherapy. ${ }^{10}$ Nishihara et al. ${ }^{49}$ used a combination of whole-brain and local radiation therapy, intrathecal injections of interferon- $\beta$, and chemotherapy with dacarbazine following the resection of a primary spinal melanoma and demonstrated the control of progression and prolonged survival. With that said, the rarity of these types of tumors make it very difficult to evaluate therapeutic options and potential at a statistically significant level.

\section{Intramedullary Metastases}

Although intramedullary metastases are considered rare, they affect $0.4 \%$ of all patients with cancer and represent $1 \%-3 \%$ of intramedullary tumors. ${ }^{6}$ They are most commonly derived from primary tumors found in the lung $(49 \%)$, breast $(15 \%)$, and lymphoma $(9 \%) .{ }^{6}$ The prognosis of patients diagnosed with intramedullary metastases is generally very poor, and thus prompt diagnosis and treatment are often crucial for survival. Recent studies have shown a median survival time of 4 months with 0 patients achieving complete remission. ${ }^{24}$ Resection may be attempted, but the lack of a clear plane of dissection often prevents achievement of GTR.

Some studies have shown the potential for the use of long-course radiotherapy, but the progressive deterioration of quality of life and neurological function pose clear limits. ${ }^{24}$ There have been a few reports on the use of chemotherapy in the treatment of intramedullary metastases in the literature, which show mixed results of efficacy. ${ }^{6}$ Hata et al. ${ }^{25}$ reported the improvement of intramedullary metastasis from lung adenocarcinoma after 2 weeks and complete response following the administration of the epidermal growth factor receptor (EGFR) inhibitor gefitinib following radiotherapy and other chemotherapeutic agents. Thus, while this particular case might have only demonstrated improvement due to an EGFR inhibitor-sensitive tumor and metastasis, the potential for chemotherapeutic agents in the treatment of intramedullary tumors warrants continued investigation.

\section{Discussion}

IMSCTs represent a rare but significant cause of neu- 
rological morbidity and mortality and affect patients of all ages. GTR remains the primary goal of treatment for most types of IMSCTs. While tumors such as ependymomas and hemangioblastomas might exhibit a clear surgical plane of dissection, more infiltrative tumors, such as astrocytomas, do not have such a plane, making complete resection impossible. ${ }^{30}$ When a plane of dissection is absent, resection is often associated with poor outcomes, despite advances in microsurgical techniques and electrophysiological monitoring during the procedure.$^{10,30}$ Radiotherapy is often the second line of treatment when resection is contraindicated or unsuccessful. However, the adverse effects of radiation are often undesirable and contribute to decreased quality of life. ${ }^{6,10}$ Chemotherapy has not been well studied for the treatment of IMSCTs, despite the therapeutic potential demonstrated in similar intracranial tumors.

The localized nature of intramedullary tumors, the lack of a clear standard of care, and the failure of current treatment regimens involving resection, radiotherapy, and chemotherapy make IMSCTs an appealing target for the development of novel, site-specific treatment strategies (Table 2). Additionally, despite progress being made in the fields of convection-enhanced delivery (CED) $)^{50,57-59}$ and ultrasonic disruption ${ }^{23,46}$ of the blood-brain barrier, these methods have not yet seen the same application in spinal cord tumors. There are, however, some preclinical studies demonstrating the utility of $\mathrm{CED}^{35,55}$ and focused ultrasound ${ }^{67}$ for delivery to the spinal cord.

Some of the main obstacles of chemotherapy include bypassing the $\mathrm{BSCB}$, lack of adequate penetration into the spinal cord parenchyma, and off-target effects associated with systemic drug administration. Intrathecal drug delivery has provided the ability to bypass the BSCB, but penetration of spinal cord parenchyma remains an issue. ${ }^{26}$ Furthermore, since intrathecal delivery does not localize to the tumor and has unhindered access to the CNS due to CSF flow, there can often be unwanted CNS side effects. Because of inherent physiological properties, such as CSF pulsations, CSF volume, heart rate, and respiratory rate, the dispersion of chemotherapeutic agents throughout the CNS can be accelerated. ${ }^{26}$ Consequently, there is an increasing interest in developing therapies capable of directed, localized drug delivery.

Unfortunately, the vast majority of new research is focused on the treatment of brain tumors, rather than spinal cord tumors. The results of these studies should, theoretically, apply to spinal cord tumors as well. Areas of new research have largely focused on 4 methods for enhancing local drug delivery: 1) enhancing drug permeability through the blood-brain barrier; 2) temporary disruption of the blood-brain barrier (e.g., ultrasound); 3) interstitial delivery of drugs (e.g., CED); and 4) the use of implantable polymer wafers. ${ }^{68}$ Several methods for enhancing drug permeability have been investigated. These include modifying drugs with molecules known to initiate receptor-mediated transcytosis via the transferrin receptor ${ }^{65}$ and lipoprotein receptor-related protein- $1 .{ }^{70}$ Permeability can also be enhanced by coating agents with polymers such as polysorbate- $80^{21}$ and poly(ethylene glycol).$^{47}$ Disruption of the blood-brain barrier can be achieved in several ways, including focused ultrasound with microbubbles, ${ }^{42,46}$ os- motic agents such as mannitol, ${ }^{44}$ and blood vessel modulators such as RMP-7. ${ }^{53}$ Interstitial drug delivery occurs via the direct injection of drugs via the stereotactic placement of a catheter with convection-enhanced (bulk flow) drug delivery. Lastly, the introduction of drug-eluting polymers has allowed the implantation of small polymer wafers adjacent to tumors in order to deliver drugs in a controlled, sustained fashion. . $^{15,19,34}$

One area of research increasingly being investigated in the field is the utilization of nanomedicine for the directed administration of therapeutic drugs. This is especially relevant for various tumors and provides the potential to bypass several obstacles encountered in regard to localization and penetration of the spinal cord parenchyma. Unfortunately, much like the treatments discussed above, the vast majority of new research has been aimed at brain tumors rather than spinal cord tumors. However, there have been promising results from nanomedicine approaches to brain tumors. For instance, Schneider et al..$^{62}$ show that the use of drug-loaded nanoparticles can be targeted to specifically bind glioblastoma cells via conjugation with the protein fibroblast growth factor-inducible 14 (Fn14). These nanoparticles successfully penetrated brain parenchyma, but specifically bound glioblastoma cells, without significant off-target effects. ${ }^{62}$ Additionally, the nanoparticles showed reduced nonspecific binding of the brain extracellular matrix. By specifically targeting cancer cells, as demonstrated via Fn14 conjugation in the Schneider et al. study, ${ }^{62}$ it is possible that nanoparticles that specifically target cancer cells could be effectively used to deliver drugs to remote tumor cells that otherwise escape resection.

To expand the study of nanomedicine to the treatment of IMSCTs, the development of both good in vitro assays as well as animal models of these tumors is essential. Fortunately, these models are available for use and have been demonstrated in both rats ${ }^{7,27,51,52}$ and rabbits ${ }^{41}$ using immortalized cell lines, ${ }^{7,41,51,52}$ as well as using cells derived from human glioblastoma tissue. ${ }^{27}$ Unique to the treatment of the spinal cord is the ability to use magnetic guidance to direct nanoparticles via an externally placed magnet on a patient's back. In fact, recent in vitro studies using a human spine model have shown the ability to achieve effective drug localization using external magnetic guidance of intrathecally delivered gold-coated nanoparticles ${ }^{36}$ Further studies by the same group demonstrated that magnetic guidance of these particles resulted in a $181 \%$ increase in the sitespecific delivery of nanoparticles compared with unguided particles. ${ }^{37}$ The development of drug delivery systems, such as these that allow for the precise localization of chemotherapeutic drugs, may represent a novel approach to treating these types of tumors (Fig. 1). This would overcome some of the obstacles faced by current chemotherapy treatments and perhaps create a better option for patients who would otherwise have a poor prognosis.

\section{Conclusions}

IMSCTs are rare but represent a very difficult to treat pathology. While most of these tumors are amenable to some extent of resection, the majority of them will require some form of adjuvant therapy, either radiation therapy or 


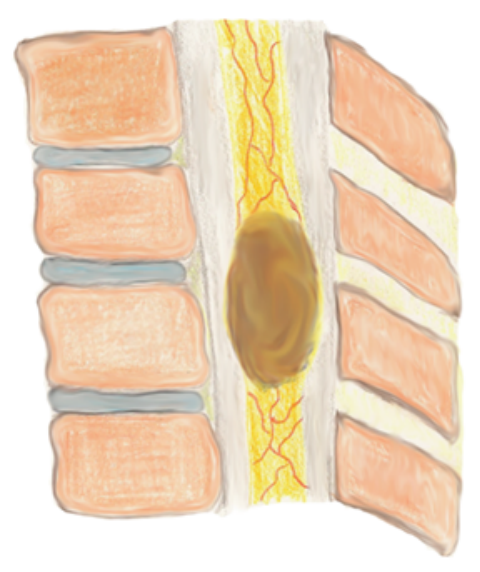

IMSCT
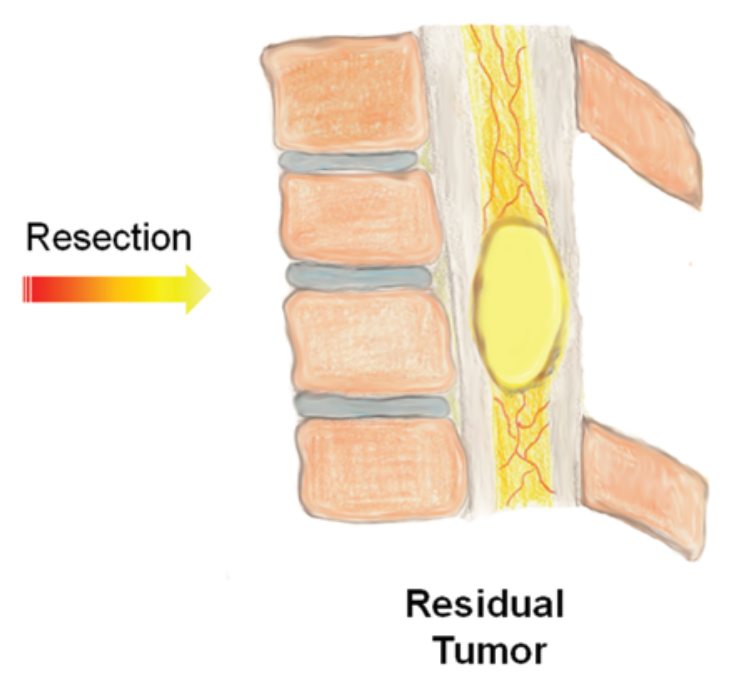
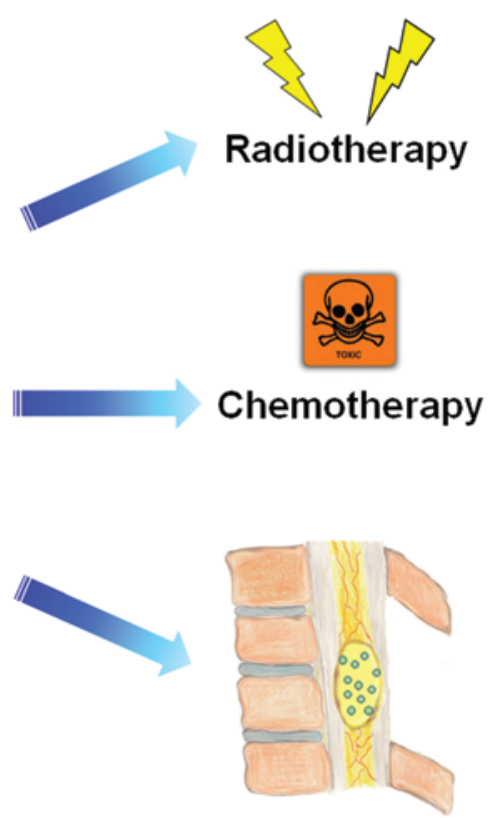

Nanomedicine

FIG. 1. Current and future treatment strategies for IMSCTs. Copyright Matthew K. Tobin. Published with permission.

chemotherapy. Unfortunately, the efficacy and safety of radiation therapy and chemotherapy are not well agreed upon and are often not beneficial for these patients. Consequently, it is imperative that novel treatments be developed to help manage these devastating tumors. One interesting area of ongoing research in developing new treatments is nanomedicine and the ability to develop localizable, targeted therapies for these tumors. While there is a significant amount of work left to be done in this field, the early results achieved with cell targeting and the magnetic guidance of nanoparticles seem promising for the future applications of this technology.

\section{References}

1. Abul-Kasim K, Thurnher MM, McKeever P, Sundgren PC: Intradural spinal tumors: current classification and MRI features. Neuroradiology 50:301-314, 2008

2. Allen JC, Aviner S, Yates AJ, Boyett JM, Cherlow JM, Turski PA, et al: Treatment of high-grade spinal cord astrocytoma of childhood with "8-in-1" chemotherapy and radiotherapy: a pilot study of CCG-945. J Neurosurg 88:215-220, 1998

3. Amini A, Chin SS, Schmidt MH: Malignant transformation of conus medullaris ganglioglioma: case report. J Neurooncol 82:313-315, 2007

4. Aoyama T, Hida K, Ishii N, Seki T, Ikeda J, Iwasaki Y: Intramedullary spinal cord germinoma-2 case reports. Surg Neurol 67:177-183, 2007

5. Babu R, Karikari IO, Owens TR, Bagley CA: Spinal cord astrocytomas: a modern 20-year experience at a single institution. Spine (Phila Pa 1976) 39:533-540, 2014

6. Balmaceda C: Chemotherapy for intramedullary spinal cord tumors. J Neurooncol 47:293-307, 2000

7. Caplan J, Pradilla G, Hdeib A, Tyler BM, Legnani FG, Bagley CA, et al: A novel model of intramedullary spinal cord tumors in rats: functional progression and histopathological characterization. Neurosurgery 59:193-200, 2006

8. Chamberlain MC: Salvage chemotherapy for recurrent spinal cord ependymona. Cancer 95:997-1002, 2002
9. Chamberlain MC: Temozolomide for recurrent low-grade spinal cord gliomas in adults. Cancer 113:1019-1024, 2008

10. Chamberlain MC, Tredway TL: Adult primary intradural spinal cord tumors: a review. Curr Neurol Neurosci Rep 11:320-328, 2011

11. Cristante L, Herrmann HD: Surgical management of intramedullary spinal cord tumors: functional outcome and sources of morbidity. Neurosurgery 35:69-76, 1994

12. Dudley RW, Torok MR, Gallegos DR, Mulcahy-Levy JM, Hoffman LM, Liu AK, et al: Pediatric low-grade ganglioglioma: epidemiology, treatments, and outcome analysis on 348 children from the surveillance, epidemiology, and end results database. Neurosurgery 76:313-320, 2015

13. Epstein FJ, Farmer JP, Freed D: Adult intramedullary astrocytomas of the spinal cord. J Neurosurg 77:355-359, 1992

14. Epstein FJ, Farmer JP, Freed D: Adult intramedullary spinal cord ependymomas: the result of surgery in 38 patients. $\mathbf{J}$ Neurosurg 79:204-209, 1993

15. Esther Gil-Alegre M, González-Alvarez I, Gutiérrez-Paúls L, Torres-Suárez AI: Three weeks release BCNU loaded hydrophilic-PLGA microspheres for interstitial chemotherapy: Development and activity against human glioblastoma cells. J Microencapsul 25:561-568, 2008

16. Farrokh D, Fransen P, Faverly D: MR findings of a primary intramedullary malignant melanoma: case report and literature review. AJNR Am J Neuroradiol 22:1864-1866, 2001

17. Feldman WB, Clark AJ, Safaee M, Ames CP, Parsa AT: Tumor control after surgery for spinal myxopapillary ependymomas: distinct outcomes in adults versus children: a systematic review. J Neurosurg Spine 19:471-476, 2013

18. Flanagan EP, O’Neill BP, Porter AB, Lanzino G, Haberman TM, Keegan BM: Primary intramedullary spinal cord lymphoma. Neurology 77:784-791, 2011

19. Grossman SA, Reinhard C, Colvin OM, Chasin M, Brundrett $\mathrm{R}$, Tamargo RJ, et al: The intracerebral distribution of BCNU delivered by surgically implanted biodegradable polymers. J Neurosurg 76:640-647, 1992

20. Guidetti B, Mercuri S, Vagnozzi R: Long-term results of the surgical treatment of 129 intramedullary spinal gliomas. J Neurosurg 54:323-330, 1981 
21. Gulyaev AE, Gelperina SE, Skidan IN, Antropov AS, Kivman GY, Kreuter J: Significant transport of doxorubicin into the brain with polysorbate 80 -coated nanoparticles. Pharm Res 16:1564-1569, 1999

22. Gupta K, Orisme W, Harreld JH, Qaddoumi I, Dalton JD, Punchihewa C, et al: Posterior fossa and spinal gangliogliomas form two distinct clinicopathologic and molecular subgroups. Acta Neuropathol Commun 2:18, 2014

23. Guthkelch AN, Carter LP, Cassady JR, Hynynen KH, Iacono RP, Johnson PC, et al: Treatment of malignant brain tumors with focused ultrasound hyperthermia and radiation: results of a phase I trial. J Neurooncol 10:271-284, 1991

24. Hashii H, Mizumoto M, Kanemoto A, Harada H, Asakura $\mathrm{H}$, Hashimoto T, et al: Radiotherapy for patients with symptomatic intramedullary spinal cord metastasis. J Radiat Res (Tokyo) 52:641-645, 2011

25. Hata Y, Takai Y, Takahashi H, Takagi K, Isobe K, Hasegawa $\mathrm{C}$, et al: Complete response of 7 years' duration after chemoradiotherapy followed by gefitinib in a patient with intramedullary spinal cord metastasis from lung adenocarcinoma. J Thorac Dis 5:E65-E67, 2013

26. Hettiarachchi HD, Hsu Y, Harris TJ Jr, Penn R, Linninger AA: The effect of pulsatile flow on intrathecal drug delivery in the spinal canal. Ann Biomed Eng 39:2592-2602, 2011 (Erratum in Ann Biomed Eng 39:2603, 2011)

27. Hsu W, Siu IM, Pradilla G, Gokaslan ZL, Jallo GI, Gallia GL: Animal model of intramedullary spinal cord glioma using human glioblastoma multiforme neurospheres. J Neurosurg Spine 16:315-319, 2012

28. Jallo GI, Freed D, Epstein F: Intramedullary spinal cord tumors in children. Childs Nerv Syst 19:641-649, 2003

29. Kane PJ, el-Mahdy W, Singh A, Powell MP, Crockard HA: Spinal intradural tumours: Part II-Intramedullary. Br J Neurosurg 13:558-563, 1999

30. Karikari IO, Nimjee SM, Hodges TR, Cutrell E, Hughes BD, Powers CJ, et al: Impact of tumor histology on resectability and neurological outcome in primary intramedullary spinal cord tumors: a single-center experience with 102 patients. Neurosurgery 68:188-197, 2011

31. Kasenda B, Ferreri AJ, Marturano E, Forst D, Bromberg J, Ghesquieres H, et al: First-line treatment and outcome of elderly patients with primary central nervous system lymphoma (PCNSL)-a systematic review and individual patient data meta-analysis. Ann Oncol [epub ahead of print], 2015

32. Kinoshita Y, Akatsuka K, Ohtake M, Kamitani H, Watanabe T: Primary intramedullary spinal cord germinoma. Neurol Med Chir (Tokyo) 50:592-594, 2010

33. Lang FF, Epstein FJ, Ransohoff J, Allen JC, Wisoff J, Abbott IR, et al: Central nervous system gangliogliomas. Part 2: Clinical outcome. J Neurosurg 79:867-873, 1993

34. Langer R, Folkman J: Polymers for the sustained release of proteins and other macromolecules. Nature 263:797-800, 1976

35. Lonser RR, Gogate N, Morrison PF, Wood JD, Oldfield EH: Direct convective delivery of macromolecules to the spinal cord. J Neurosurg 89:616-622, 1998

36. Lueshen E, Venugopal I, Kanikunnel J, Soni T, Alaraj A, Linninger A: Intrathecal magnetic drug targeting using goldcoated magnetite nanoparticles in a human spine model. Nanomedicine (Lond) 9:1155-1169, 2014

37. Lueshen E, Venugopal I, Soni T, Alaraj A, Linninger A: Implant-assisted intrathecal magnetic drug targeting to aid in therapeutic nanoparticle localization for potential treatment of central nervous system disorders. J Biomed Nanotechnol 11:253-261, 2015

38. Madhukar M, Maller VG, Choudhary AK, Iantosca MR, Specht CS, Dias MS: Primary intramedullary spinal cord germinoma. J Neurosurg Pediatr 11:605-609, 2013

39. Madhusudan S, Deplanque G, Braybrooke JP, Cattell E, Tay- lor M, Price P, et al: Antiangiogenic therapy for von HippelLindau disease. JAMA 291:943-944, 2004

40. Malmström A, Grønberg BH, Marosi C, Stupp R, Frappaz D, Schultz H, et al: Temozolomide versus standard 6-week radiotherapy versus hypofractionated radiotherapy in patients older than 60 years with glioblastoma: the Nordic randomised, phase 3 trial. Lancet Oncol 13:916-926, 2012

41. Mavinkurve G, Pradilla G, Legnani FG, Tyler BM, Bagley $\mathrm{CA}$, Brem $\mathrm{H}$, et al: A novel intramedullary spinal cord tumor model: functional, radiological, and histopathological characterization. J Neurosurg Spine 3:142-148, 2005

42. McDannold N, Arvanitis CD, Vykhodtseva N, Livingstone MS: Temporary disruption of the blood-brain barrier by use of ultrasound and microbubbles: safety and efficacy evaluation in rhesus macaques. Cancer Res 72:3652-3663, 2012

43. Miller DJ, McCutcheon IE: Hemangioblastomas and other uncommon intramedullary tumors. J Neurooncol 47:253270,2000

44. Miyagami M, Tsubokawa T, Tazoe M, Kagawa Y: Intra-arterial ACNU chemotherapy employing $20 \%$ mannitol osmotic blood-brain barrier disruption for malignant brain tumors. Neurol Med Chir (Tokyo) 30:582-590, 1990

45. Mottl H, Koutecky J: Treatment of spinal cord tumors in children. Med Pediatr Oncol 29:293-295, 1997

46. Nance E, Timbie K, Miller GW, Song J, Louttit C, Klibanov $\mathrm{AL}$, et al: Non-invasive delivery of stealth, brain-penetrating nanoparticles across the blood-brain barrier using MRI-guided focused ultrasound. J Control Release 189:123-132, 2014

47. Nance EA, Woodworth GF, Sailor KA, Shih TY, Xu Q, Swaminathan G, et al: A dense poly(ethylene glycol) coating improves penetration of large polymeric nanoparticles within brain tissue. Sci Transl Med 4:149ra119, 2012

48. Neumann HP, Eggert HR, Weigel K, Friedburg H, Wiestler OD, Schollmeyer P: Hemangioblastomas of the central nervous system. A 10-year study with special reference to von Hippel-Lindau syndrome. J Neurosurg 70:24-30, 1989

49. Nishihara M, Sasayama T, Kondoh T, Tanaka K, Kohmura E, Kudo H: Long-term survival after surgical resection of primary spinal malignant melanoma. Neurol Med Chir (Tokyo) 49:546-548, 2009

50. Patel SJ, Shapiro WR, Laske DW, Jensen RL, Asher AL, Wessels BW, et al: Safety and feasibility of convectionenhanced delivery of Cotara for the treatment of malignant glioma: initial experience in 51 patients. Neurosurgery 56:1243-1253, 2005

51. Pennant WA, An S, Gwak SJ, Choi S, Banh DT, Nguyen AB, et al: Local non-viral gene delivery of apoptin delays the onset of paresis in an experimental model of intramedullary spinal cord tumor. Spinal Cord 52:3-8, 2014

52. Pennant WA, Sciubba DM, Noggle JC, Tyler BM, Tamargo RJ, Jallo GI: Microsurgical removal of intramedullary spinal cord gliomas in a rat spinal cord decreases onset to paresis, an animal model for intramedullary tumor treatment. Childs Nerv Syst 24:901-907, 2008

53. Prados MD, Schold SC SC Jr, Fine HA, Jaeckle K, Hochberg F, Mechtler L, et al: A randomized, double-blind, placebocontrolled, phase 2 study of RMP-7 in combination with carboplatin administered intravenously for the treatment of recurrent malignant glioma. Neuro Oncol 5:96-103, 2003

54. Raco A, Esposito V, Lenzi J, Piccirilli M, Delfini R, Cantore G: Long-term follow-up of intramedullary spinal cord tumors: a series of 202 cases. Neurosurgery 56:972-981, 2005

55. Ratliff JK, Oldfield EH: Convection-enhanced delivery in intact and lesioned peripheral nerve. J Neurosurg 95:10011011,2001

56. Rudà R, Gilbert M, Soffietti R: Ependymomas of the adult: molecular biology and treatment. Curr Opin Neurol 21:754-761, 2008

57. Sampson JH, Akabani G, Archer GE, Bigner DD, Berger MS, 
Friedman AH, et al: Progress report of a Phase I study of the intracerebral microinfusion of a recombinant chimeric protein composed of transforming growth factor (TGF)-alpha and a mutated form of the Pseudomonas exotoxin termed PE-38 (TP-38) for the treatment of malignant brain tumors. J Neurooncol 65:27-35, 2003

58. Sampson JH, Brady M, Raghavan R, Mehta AI, Friedman $\mathrm{AH}$, Reardon DA, et al: Colocalization of gadolinium-diethylene triamine pentaacetic acid with high-molecular-weight molecules after intracerebral convection-enhanced delivery in humans. Neurosurgery 69:668-676, 2011

59. Sampson JH, Brady ML, Petry NA, Croteau D, Friedman $\mathrm{AH}$, Friedman HS, et al: Intracerebral infusate distribution by convection-enhanced delivery in humans with malignant gliomas: descriptive effects of target anatomy and catheter positioning. Neurosurgery 60:ONS89-ONS99, 2007

60. Sandalcioglu IE, Gasser T, Asgari S, Lazorisak A, Engelhorn T, Egelhof T, et al: Functional outcome after surgical treatment of intramedullary spinal cord tumors: experience with 78 patients. Spinal Cord 43:34-41, 2005

61. Schneider C, Hidalgo ET, Schmitt-Mechelke T, Kothbauer KF: Quality of life after surgical treatment of primary intramedullary spinal cord tumors in children. J Neurosurg Pediatr 13:170-177, 2014

62. Schneider CS, Perez JG, Cheng E, Zhang C, Mastorakos $\mathrm{P}$, Hanes J, et al: Minimizing the non-specific binding of nanoparticles to the brain enables active targeting of Fn14positive glioblastoma cells. Biomaterials 42:42-51, 2015

63. Seystahl K, Weller M, Bozinov O, Reimann R, Rushing E: Neuropathological characteristics of progression after prolonged response to bevacizumab in multifocal hemangioblastoma. Oncol Res Treat 37:209-212, 2014

64. Sharma GK, Kucia EJ, Spetzler RF: Spontaneous intramedullary hemorrhage of spinal hemangioblastoma: case report. Neurosurgery 65:E627-E628, 2009

65. Shin SU, Friden P, Moran M, Olson T, Kang YS, Pardridge
WM, et al: Transferrin-antibody fusion proteins are effective in brain targeting. Proc Natl Acad Sci U S A 92:2820-2824, 1995

66. Sun HI, Özduman K, Usseli MI, Özgen S, Pamir MN: Sporadic spinal hemangioblastomas can be effectively treated by microsurgery alone. World Neurosurg 82:836-847, 2014

67. Wachsmuth J, Chopra R, Hynynen K: Feasibility of transient image-guided blood-spinal cord barrier disruption, in Ebbini ES (ed): 8th International Symposium on Therapeutic Ultrasound. Minneapolis, MN: American Institute of Physics, 2009, Vol 1113, pp 256-259

68. Woodworth GF, Dunn GP, Nance EA, Hanes J, Brem H: Emerging insights into barriers to effective brain tumor therapeutics. Front Oncol 4:126, 2014

69. Yang C, Li G, Fang J, Wu L, Yang T, Deng X, et al: Intramedullary gangliogliomas: clinical features, surgical outcomes, and neuropathic scoliosis. J Neurooncol 116:135-143, 2014

70. Yuan H, Goetz DJ, Gaber MW, Issekutz AC, Merchant TE, Kiani MF: Radiation-induced up-regulation of adhesion molecules in brain microvasculature and their modulation by dexamethasone. Radiat Res 163:544-551, 2005

\section{Author Contributions}

Conception and design: Mehta. Acquisition of data: Mehta, Tobin, Geraghty. Analysis and interpretation of data: all authors. Drafting the article: all authors. Critically revising the article: all authors. Reviewed submitted version of manuscript: Mehta, Geraghty, Engelhard, Linninger. Approved the final version of the manuscript on behalf of all authors: Mehta.

\section{Correspondence}

Ankit Mehta, Department of Neurosurgery, University of Illinois at Chicago, 912 S. Wood St., M/C 799, Chicago, IL 60612. email: ankitm@uic.edu. 